\section{Social Science Research and Northern Development}

All the indications are that Canada is finally about to take her North more seriously, and to accept the fact that that region is not a peripheral part of the nation, but is at the very core of its being. In addition, there seems to be little doubt that the Canadian North is on the verge of an outbreak of social science. The Twentieth Anniversary issue of Arctic (March 1966) contained a number of statements about the importance of social science research in the North and lamentations about the shortage of specialists and studies in that field.

But pop art versions of northern development still persist; in these the opening-up of the Canadian North is equated with the settlement of the American West, and the degree of enthusiasm and popular support gathered is generally inversely proportionate to the amount of knowledge the promoters have about the North; it must be remembered that it took a hundred years to demythologize the American West and to separate the real from the imaginary.

The talk of a massive assault upon the economic and social problems of the North makes anyone wince who has even the slightest first hand knowledge of that region and of development there to date, and has any concern for human values. There is still the persistent belief that a Canadian North with a population of one million would be, in some mysterious way, a thousand times better than a north containing 1,000 people. Mere quantity is no criterion for development.

The North is a quality environment. It demands a high level of science and technology to establish the limits of possible operations, and to work within these limits. Northern development has involved, and will involve, the investment of very large sums of money in tools of various kinds - mining machinery, educational systems, transportation networks. But the aim of development is man - man becomes the means and the end. The tools will be useless without people to operate them, and northern development will be an exercise in national futility if the means used in the process are divorced from the ends. Of late, it has become customary to talk of human resources. This conjures up visions of people being seen as factors of production only, and not as ends in themselves. There is ample evidence that if people in an areaespecially in a traditional area where they are sensitive to non-verbal messages - get the impression that they are being manipulated for the ends of others, and are not working together in enterprises of mutual concern, then they will quite quickly turn off.

The recently created Mid-Canada Development Corridor Foundation Inc.1,2 sees Canada's Middle North being "opened up" and the "vast treasure house of natural resources" forming the basis for a population build-up in the areas between Canada's settled southern belt and the Arctic's southern limit. The development plan envisages the expenditure of $\$ 5$ billion by the Canadian government. There will be a conference in January 1969, and the participants will then travel to USSR to study their northern development. Canadians seem to have a masochistic urge to compare the lack of achievement in their North with what the Russians have accomplished. But in human terms, such a comparison is like trying to compare chalk and cheese.

Development should widen possibilities for people, but one unfortunate feature of Canada's northern development to date has been the way in which one single possibility has been pressed to the exclusion of all others. Currently it is oil that is going to develop the North, and the amount of money, time and effort being poured into the hunt for oil seems to be blinding the federal government to other possibilities that would help to create good jobs for the people and provide a firmer basis for the economy than the exploitation of one single resource with an uncertain future. In 1967-68, the federal government invested nine million dollars in a search for oil in the Arctic Islands, while, at the same time, health services in the Northwest Territories were curtailed. Apart from the human aspect, even spokesmen for the oil industry are not happy with this attempt to find new reserves of oil when existing oilfields are having difficulty in finding a market.

The federal government has been demonstrating some sort of psychic split - a search for quick wealth to pay for running the north and a seeming lack of concern for the people there. This is illustrated poignantly by Art Sorensen in an article on Churchill, Manitoba; ${ }^{3}$

It is incongruous to see a Winnipeg-built Black Brant rocket streaking through the atmosphere while a few miles away an Indian woman digs into one of the several coal bins scattered throughout her village. Such impressionistic statements reveal the basic problem. Here two ways of life, perhaps two modes of thought meet - or fail to meet. An attempt has been made to 
recreate an urban, southern Canadian way of life in a cold, harsh, remote, barren wilderness. Ottawa has developed the North as if it were merely a suburb of that city. The material aspects of the culture of southern Canada (or more correctly, of the United States) - houses, cars, etc. - are but the outward symbols of a mode of thinking that must be changed if the North is to develop. George Rogers' quotation of the boomer's phrase building Fifth Avenue on the tundra 4 in connection with Alaska's development to date sums up the situation admirably, and shows that this sort of approach to northern development is not confined to Canada.

What has all the money, time, effort and nervous energy expended on the North so far brought about? Today, the northern Indians and Eskimos are still poor, depressed, and at the bottom of the heap of humanity. Yet they are a quality population who managed to live and raise families under incredibly hard conditions. There is still the feeling that these people are somehow behind us, waiting to be led towards the light. Despite the demand by the government for people to go North and develop the area, the same government manages to give the impression that there are too many Eskimos and Indians. At their Spring 1968 Session, the Council of the Northwest Territories noted high infant mortality in the North, squalid living conditions, reduced health services, and came up with the inevitable statement that birth control services were needed. If Eskimo women keep losing children - a source of wealth and comfort to them - then no amount of propaganda about birth control will convince them of the need to keep the population down. The Northwest Territories showed a curious paradox in 1968 - all the official talk was of boom and economic expansion and the need for labour in the North, whereas the Territorial Council endeavoured to keep the native people from reproducing.

Those who see the Canadian North peopled by thousands of "settlers" do not seem to realize that the census count takes place in the summer and includes many transients. Remove the transients and the civil servants, and how many permanent northern residents remain? We are ignorant of one simple elementary fact about the North - its permanent population.

Two well defined flows of population can be identified in the Territories today. Highly skilled young people are moving in to work in the mines and in government. The boomers, the transients, some older people and Eskimos and Indians are moving out. Those who are left are getting rather fed up with the resources of the Territories being developed in such a way that they benefit only outside interests. The results of such exploitation can be seen in Alaska, where native peoples have claimed that the resources of the state belong to them $;^{5}$ this move is beginning in Canada. ${ }^{6}$

Viewing such trends as these, there is a tendency to think about a big program of social science research to solve the problems there. Of course, social science research is needed, but it must be handled in a certain way. A great deal of research in the physical and biological sciences has been done in the North. It would be interesting to determine how many people the scientists have employed, and how local people viewed the jobs they got with fisheries studies, expeditions, etc. The people who have worked in the North in scientific research have been able to see reality stripped down to its bare bones, as it were, and to understand complex relationships that escape easy analysis in crowded, richer, warmer environments.

The people are also getting fed up with the questions asked by research workers, and never seeing the results of the research. Anyone plugged into the Canadian Northern network soon gets the message about the social science research there. In Northern Ontario an American psychologist nearly ends up in the river after researching the Indians; forty anthropologists have visited one settlement in the Northwest Territories in one summer; some Indians in Ontario have closed their reserves to research workers; a senior government official blasts social scientists for being useless to the administration; a group of academics in a British Columbia settlement bought their information from the town drunk; and so on. Vague rumours, exaggerated statements, dubious stories distorted in their passage through space and time - but they reveal a basic problem in social science research. There are relatively few people in the Canadian North, and they are not inclined to co-operate with those who treat them merely as a means to an end.

Quantity of research by itself is certainly not an adequate gauge of utility. The recent demise of Project Camelot 7 - an attempt at large scale social science research on insurgency backed with military funds - shows that a high degree of sensitivity to local conditions is required. And yet the outside "boomers" who want to see the North develop seem to lack this sensitivity.

For social science research to have any validity, it must be theoretically sound, and practically applicable. It must also be planned and carried out in an ethical manner. 
One of the main differences between physical and biological sciences and social science is that the former are experimental, and the latter is still largely observational. People do not like being made subjects for experiment. If their co-operation is sought and obtained in carrying out research projects that are of interest and value to them, then they will co-operate. But if they are made to feel like butterfiles being pinned down on a card in the interests of research, then they are not likely to take kindly to social scientists.

A social scientist should seek to understand why individuals or groups behave in a certain way, not merely to describe them. Not all make the attempt any more than did some early missionaries mentioned by J. Russell Smith, 8 the American Geographer. Smith opened his textbook on North America with the question: "Hell is hot. Did you ever wonder why?" Then he went on to describe how missionaries in Greenland nonplussed the Eskimos by preaching about Hell and its fires. To the Eskimos, Hell sounded like a very desirable place to live - but did they have to lie, cheat, steal and murder to be assured of a place there?

Moreover, a social scientist should seek to understand and not to condemn. The report or study that contains complaints about the stupidity of the people and rants on about their faults reveals a great deal more about the author and the research worker than it does about the people studied. Science implies that research workers become curious about what they are studying - not furious. This does not mean that the social scientist cannot have a human engagement and commitment to alleviate misery and stress; it means only that he has to define his role (or roles) and understand where he stands at any one time.

There has been too much of a tendency in the past to regard northern problems as problems of the North only, and to attempt to solve them in isolation from the general stream of thought on development, and from the main body of the nation. Any research on northern development inevitably brings the worker into contact with the considerable body of literature on socio-economic development in the rest of the world. Books by Hoselitz ${ }^{9}$ and by Spengler and Braibanti, ${ }^{10}$ for example, contain a wealth of ideas and information relevant to northern development. One major problem in the North is isolation and research done there can float around, unrelated to the body of theory on development and its problems that has arisen out of studies in other parts of the world. For the North can be seen as a great outdoor laboratory for the developing world - or an edge on which all men can have their teeth and their minds honed to help in a better understanding of the entire world. There have already been significant achievements: The Mackenzie Delta Project, run by the Northern Science Research Group of the Department of Indian Affairs and Northern Development; the work of the Inuvik Research Laboratory; both have shown how research can serve the needs of the local people, and help them to identify and deal with their problems. In the past five years there has also been an encouraging growth of northern research institutes in Canada associated with universities. Alaska, too, has programs such as the Alaska Rural School Project and the College Orientation Program for Alaska Natives. All these developments need to be examined, understood, documented and communicated to others.

The problems of northern development can be grouped under the following headings: space (how can a nation control, operate efficiently in, and develop a large land mass with a sparse population? How can the centre of power, where decisions are made, be related to the periphery where action is carried out?); culture contact (traditional and western ways and their interaction); social change (how can a high level of science and technology be introduced into an area which has only recently come into the stream of modern history?); and resource endowment and development (what constitutes a resource, and how can it be developed without insult to other potential resources and to people?)

A great deal has been done in the North already; it needs to be evaluated and extended. Co-ordination is a word that upsets scientists; it conjures up visions of administrators telling them how many pencils they can have, or controlling their research. It is very hard to assess the "output" of research, and in our product-oriented western world there seems to be little money for people who merely wish to follow their curiosity to its very end. Co-ordination can be effected in two ways - by arranging for information and material to be brought together in one place and between covers from time to time and made available freely to all, and by encouraging research workers to contact and co-operate with everyone in a particular field or a particular area of interest. In time, it may be possible to turn the North into the sort of international research environment in the social sciences as Antarctica is in the physical sciences. This process need not involve the creation of large bureaucracies. The International Geophysical Year of 1957- 
58 had a total secretariat at peak of eight people, and everyone who took part in that knows what a satisfying experience it was, professionally and personally.

We still, in Canada, have to answer the basic question: What is the North all about? What good is it? The answers will not come easily, but they will come in time if we understand how man lived there in the past and can live in the future. If the stress is not laid on the pathological aspects of life north of sixty - a failing of social science in the more southerly areas - then we may be able to use science as a method of understanding and exerting a greater degree of control over the physical and social environment in a way that will benefit all. Already it is not so much that we are developing the North but that the North is developing us.

Social science research in the Canadian North could add new dimensions to our knowledge of the way the world works; or it could lead to massive disasters. In our electronic world, we are moving from the extension of man's muscle to the extension of his mind. What the machines did to men's bodies during the Industrial Revolution, the electronic media might do to men's minds during the Electronic Revolution. And we shall see this trend sooner in the North than elsewhere. Everyone concerned or involved in northern development should be aware of this. And no one should be more aware of this than the social scientist, as he stands on the very frontier of knowledge in a frontier land.

\section{ACKNOWLEDGEMENT}

The views expressed herein are my own, and not necessarily those of the Centre or of the Arctic Institute. I would like to acknowledge the very considerable assistance I have received in my work in social science in the north from Dr. George Rogers (University of Alaska - Economics), Dr. Richard Cooley (University of Washington Geography and Public Affairs), Dr. D. Shimkin (University of Illinois - Anthropology and Geography) and Dr. Trevor Lloyd (McGill University - Geography) among many others.

\section{Jim Lotz}

CANADIAN RESEARCH CENTRE FOR ANTHROPOLOGY, OTTAWA.

\section{REFERENCES}

1Osler, Jack. 1968. Corridor concept studied. Edmonton: Edmonton Journal, September 6 .
2Cowan, Edward. 1968. Vast plan urged for mid-Canada. New York: New York Times, September 15.

3Sorensen, Art. 1968. Manitoba Indians sympathy seekers. Edmonton: Edmonton Journal, January 20.

${ }^{4}$ Rogers, George. 1962. The future of Alaska: Economic consequences of Statehood. Baltimore: Johns Hopkins Press, p. 270.

5Rogers, George. 1967. Eskimo administration in Alaska. Arctic, 20: 269-70.

${ }^{6}$ Indians challenge treaty. News of the North 26 (28), 11 July 1968.

7Bucksar, Richard. 1967. Operation Camelot. Canadian Welfare, 14: 16-21.

8Smith, J. Russell. 1925. North America. New York: Harcourt, Brace and Co. 466 pp.

${ }^{9}$ Hoselitz, Bert. 1960. Sociological aspects of economic growth. Glencoe: The Free Press. $250 \mathrm{pp}$.

10Spengler, J. and R. Braibanti (Eds.). 1961. Traditions, values and socio-economic development. Durham: Duke University Press, 305 pp.

\section{Overwintering Birds \\ Observed along the Mackenzie-Great Slave Lake Highways}

\section{INTRODUCTION}

The purpose of this paper is to record the birds observed near Rae, Northwest Territories $\left(62^{\circ} 45^{\prime} \mathrm{N} ., 116^{\circ} 5^{\prime} \mathrm{W}.\right), 12$ to $21 \mathrm{De}-$ cember 1965 and at the University of Alberta Biological Station at Heart Lake, Northwest Territories $\left(60^{\circ} 51^{\prime} \mathrm{N} ., 116^{\circ} 38^{\prime} \mathrm{W}\right), 19$ to 28 December 1966. During these periods records were kept of the birds seen at these locations and along the highways connecting these two points (Fig. 1). Also included are observations made by Roy Dyke 6 October to 21 April 1966 at the Biological Station.

Winter distributional records of the avifauna in subarctic regions of northern Canada are incomplete.

\section{DESCRIPTION OF THE AREA}

The area in which observations were made falls within the Hay River, Upper Mackenzie and Northwestern Transition sections of the transcontinental Boreal Forest Region. ${ }^{1}$ A more general classification places most of the area within the Canadian life zone. To the 